\title{
Methane Production via High Temperature Steam Electrolyser from Renewable Wind Energy: A German Study
}

\author{
Nathalie Monnerie, Anis Houaijia, Martin Roeb, Christian Sattler \\ Institute of Solar Research, German Aerospace Center (DLR), Cologne, Germany \\ Email: nathalie.monnerie@dlr.de
}

Received 23 February 2015; accepted 19 April 2015; published 22 April 2015

Copyright (C) 2015 by authors and Scientific Research Publishing Inc.

This work is licensed under the Creative Commons Attribution International License (CC BY). http://creativecommons.org/licenses/by/4.0/

c) (i) Open Access

\section{Abstract}

The transformation of the energy supply needs further development of energy storage technologies in order to integrate the fluctuating renewable energy. The conversion of renewable wind power into green methane offers a technical approach with the necessary storage and transport capacities. Thus, the concept of Power-to-Gas which is illustrated here by the coupling of wind energy with a High Temperature Steam Electrolyser (HTSE) and a methanation unit enabling the production of green fuel like hydrogen and methane is presented is this paper. In fact, hydrogen can be used as energy carrier as well for the production of green fuels, like methane which is simpler to store and to transport and which can be thus used as storage medium for the stabilization of the electrical power supply as well as fuel for transport and heat sector. Its production using high temperature electrolysis is able to reduce the carbon dioxide emissions if performed with renewable resources. This is the case if the electricity needed for the HTSE comes from a wind turbine and the $\mathrm{CO}_{2}$ needed for the methanation step comes from biogas. For such a plant, the location and the boundary conditions have a great importance. Thus, this study considers the coupling of a HTSE with a wind turbine and a methanation reactor, and focuses about the site selection, depending of the geographical and economic considerations. The study is limited first to the European area. Schleswig-Holstein is found as a very good location for this plant. It is one of the regions with the largest wind reserves in Germany. This region has also available a lot of biogas and meets all the other necessary requirements.

\section{Keywords}

Methane, Hydrogen, High Temperature Steam Electrolysis, Wind Energy, Biogas 


\section{Introduction}

Energy derived of the consumption of conventional fossil resources is not environmental-friendly for the human development. Consequently, the interest for the exploitation of renewable energy sources has massively increased during the last years with the last objective to become eventually full independent from fossil fuel energy. Within these broad renewable resource types, renewable generation heat technologies have been developed. Thus renewable heat can be produced for example from solar energy, bioenergy and geothermal energy [1]. Solar thermal collectors produce heat derived from solar radiation by heating a fluid circulated within the collector. Direct-use geothermal applications use the heat that is stored in rock and trapped in vapour or liquids. Modern on-site biomass technologies include efficient wood burning stoves, municipal solid waste incineration, pellet boilers and biogas. Modern biomass combustion to produce heat is a mature technology [2] [3].

In parallel, a variety of commercially available renewable electricity generation technologies have been deployed including photovoltaics, hydropower, stand-alone bio-power, co-fired onshore wind, and fixed-bottom offshore wind [4]. In this context, wind energy has become an important resource and its management has an increasing signification [5]. Windmills have been used for power production for a long time. Among renewable energy, wind has a very big capacity in terms of supply for the future energy mix. However, wind power is variable and has thus some particularities. It is a diffuse energy that cannot be stored facilely [6]. Consequently, some solutions are needed to better sore or manage the surplus electricity produced by the wind energy in order to optimize its use. It was envisaged in the frame of the European project Adel [7] that the production of green synthetic fuels like methane can bring stability to an electricity grid having a high share of renewable energy and can replace fossil fuels. Therefore, it is interesting to couple wind energy with a process enabling the production of green fuel, which can be stored or transported. Thus the renewable electricity obtained from wind power can be converted first into green hydrogen to store wind power in the form of transportable and useful chemical energy. This hydrogen can be then converted into synthetic fuels like methane which is thus a totally renewable fuel if produced from green hydrogen, produced itself from renewable electricity and water, like in the water splitting process. This process finds thus its places in the concept of power-to-gas. Actually with the power to gas concept electrical power coming from renewable energy sources can be converted into hydrogen or synthetic fuels like methane which can be stored in the gas system. This is a way to store large amounts of electricity from renewable energy sources in the long term [8].

The splitting of water can be achieved through electrolysis and thermochemical cycles. Water electrolysis consists in the decomposition of water into hydrogen and oxygen. It can so produce on large scale carbon-free hydrogen using electricity from $\mathrm{CO}_{2}$-free energy sources [9] [10] and can thus contribute to augment the part of renewable energy in the whole energy system. The electrolysis of steam, known as the high temperature steam electrolysis (HTSE), operates at higher temperatures in the range of $700^{\circ} \mathrm{C}-1100^{\circ} \mathrm{C}$. In this process, a part of the energy needed for the electrolysis reaction is provided by heat saving thus a part of the electricity demand, which is a big advantage of the HTSE. Another advantage is the higher energy efficiency in comparison with the low temperature electrolysis because of reduced cell potential. Thus HTSE is a promising process for emissionfree hydrogen production from water and offers positive outlook for efficient use of renewable energy sources. Indeed, electricity and heat needed for the HTSE can be provided by renewable energy like wind energy and biogas.

This hydrogen produced will be fed to a methanation unit, which can be running also with renewable energy like biogas. This methanation unit produces thus methane as bio fuel and as a long-term storage medium for the energy sector while the recovered heat of the methanation reaction is used for the HTSE. Actually methane is easier to handle and can be stored more facilely than hydrogen. Furthermore, the transportation and storage facilities exist already and are mature. Immense storage capacity in the form of storage tanks and pipeline grids are already available in many countries. This concept offers a solution to the challenge of integrating more and more renewable energy into the global energy mix. The technology can indeed store electrochemically the surplus wind energy by producing first hydrogen and then methane.

The suitability of locations of this plant depends on the energy sources and water source availability. The infrastructures as well as economic considerations need also to be taken into account. The determination of the plant location will allow defining further boundary conditions of the plant. The overall purpose of this study is to define in detail the boundary conditions related to the HTSE coupled with a wind turbine and a methanation unit as well as to select a good location for such a plant in Europe. The paper is structured as follows: Section 2 de- 
scribes the studied technology and presents the flow sheet of the process. Section 3 introduces the methodology used to select an appropriate location for the plant and Section 4 presents the results and discusses them. Finally, the conclusion will indicate the most important outcomes of this study and proposals for further works.

\section{Description of the Technology}

\subsection{Concept}

The wind technology has been investigated as a potential renewable electricity source for the HTSE The process presented in this paper couples a HTSE with wind energy and in a further methanation step with biogas in order to produce methane as green fuel. The main part of this process is the HTSE. It is made up of the oxy-reduction of water molecules, driven by a direct electric current and the hydrogen so obtained has a high purity. An advantage of the HTSE working at $700^{\circ} \mathrm{C}$ is that its electricity consumption is lower than the one of a low temperature electrolyser (PEM or alkaline) because one part of the energy needed is furnished by heat energy, which leads to lower operation costs. In the proposed process defined in this paper, the electricity needed for the HTSE is coming from a traditional wind turbine while the water is evaporated by the heat coming from a methanation unit. The hydrogen produced by the HTSE is then sent to amethanation unit, to produce methane following the Sabatier process, which consists of the reaction of hydrogen with carbon dioxide.

The scheme of the plant is represented on Figure 1. The complete system consists of the following four main sections:

- The HTSE unit.

- The wind turbine system.

- The heat recovery system.

- The methanation unit.

\subsection{High Temperature Steam Electrolysis}

The splitting of water can be achieved through high temperature steam electrolysis, which uses a combination of electrical energy and high temperature heat. The chemical reactions, which take place in the electrolyser, are given as follows:

- On the cathode side:

$$
\mathrm{H}_{2} \mathrm{O}+2 \mathrm{e}^{-} \rightarrow \mathrm{H}_{2}+\mathrm{O}^{2-}
$$

- On the anode side:

$$
\mathrm{O}^{2-} \rightarrow 0.5 \mathrm{O}_{2}+2 \mathrm{e}^{-}
$$

Both reactions give the overall water splitting reaction:

$$
\mathrm{H}_{2} \mathrm{O} \rightarrow \mathrm{H}_{2}+\mathbf{0 . 5 \mathrm { O } _ { 2 }}
$$

The HTSE process is performed using SOEC (Solid Oxide Electrolysis Cell). SOEC consists of a three-layer solid structure (cathode, anode and electrolyte) and an interconnect plate. The electrolyte is a gas-tight ceramic

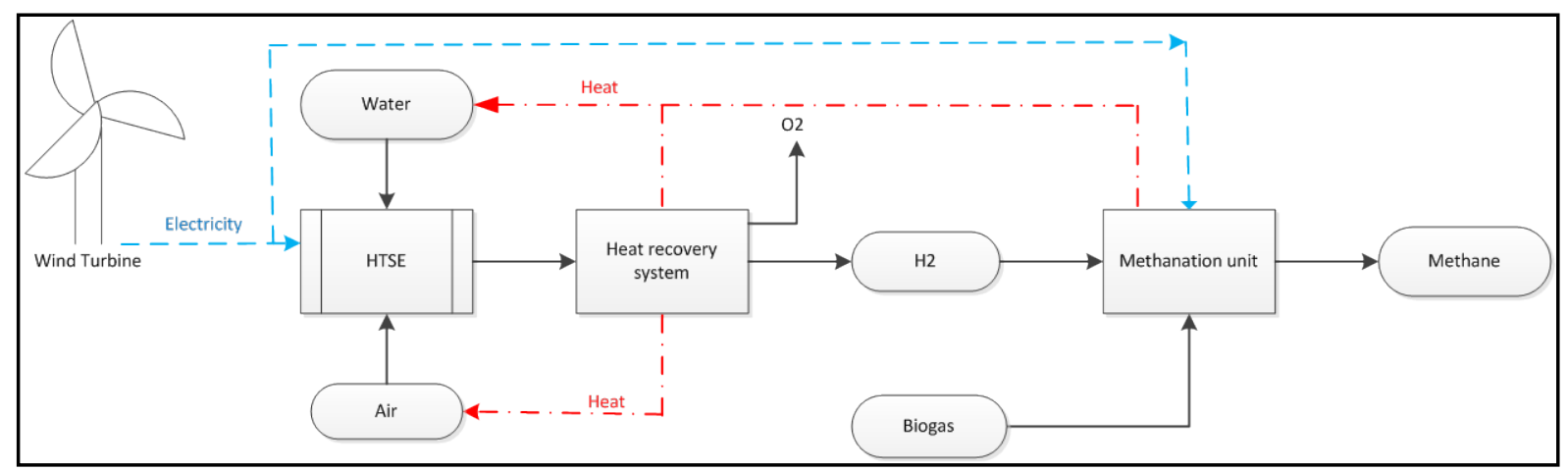

Figure 1. Scheme of the wind turbine coupled with HTSE. 
membrane that can conduct ions and is situated between two porous electrodes based on yttria stabilized zirconia (YSZ) [11]. The HTSE works in the thermoneutral mode. In this mode, outlet gases $\left(\mathrm{H}_{2} / \mathrm{H}_{2} \mathrm{O}\right.$ and $\left.\mathrm{O}_{2}\right)$ have the same temperature as the inlet gases $\left(\mathrm{H}_{2} \mathrm{O} / \mathrm{H}_{2}\right)$. The operating temperature of the electrolyser is an important factor in terms of efficiency of the HTSE process. A high operating temperature conducts to degradation of the solid oxide electrolysiscell. On the other hand a low operating temperature has a negative influence on the efficiency of the stack [12]. Thus, it was decided in this study in the frame of the European project ADEL [7] to operate the electrolyser at $700^{\circ} \mathrm{C}$, which is an acceptable compromise regarding durability and efficiency of the stack. Furthermore, to guarantee a satisfactory lifetime of the stack components, the steam conversion is limited to $60 \%$. The gas at the outlet of the electrolyser is conducted to heat recovery system where it passes heat to the incoming steam. Sweeping air is used to flush the produced oxygen from the cathode in order to keep away from safety issues of handling pure oxygen at $700^{\circ} \mathrm{C}$. In order to optimize the system efficiency the sweeping air flow rates should be minimized. The system design has been based on a molar air-steam ratio of unity.

\subsection{Wind Turbine System}

The amount of energy (MWh) produced by a wind turbine each year depends on many parameters, but the most important factors are the wind speed at hub-height, and the size and type of the turbine. Most of the wind turbines can be classified as either Horizontal-Axis Wind Turbines (HAWTs), which have blades that rotate around a horizontal axis parallel to the wind, or Vertical-Axis Wind Turbines (VAWTs), which have blades that rotate around a vertical axis. The HAWT rotor is placed on the top of a tall tower, which allows to access to stronger winds. The most common type of modern HAWT is the classic "Danish" design of three-blade, upwind and pitch regulated concept. The wind turbine used in the presented plant to provide electrical energy to the HTSE is a horizontal axis wind turbine.

\subsection{Heat Recovery System}

The out coming gases from the HTSE stack are coupled with a heat recovery system, consisting of heat exchangers. The heat of the outlet flows is thus recovered and the steam entering the electrolyser is heated up to the operating temperature of the electrolyser at $700^{\circ} \mathrm{C}$. Nevertheless an additional electrical heater is considered for the transient conditions in order to reach the operating temperature of the electrolyser. The heat recovery system including the one of the methanation unit allows evaporation and heating of the water required for the electrolyser but there is not sufficient heat to heat completely the sweep gas which has to be taken into account. Thus a second electrical heater is added to heat the sweep gas to $700^{\circ} \mathrm{C}$. In this manner the sweep gas temperature can be controlled and fixed requirements are testified for the sweep gas in the electrolyser.

\subsection{Methanation Unit}

Methane is produced applying the Sabatier process. The Sabatier process is currently debated as option for a "power-to-gas" scenario. The process considered in this paper represents an example of what can be an integration of the renewable electricity in a larger energy system. The Sabatier process consists of the reaction of hydrogen with carbon dioxide contained in biogas in the studied process. This reaction takes place in the presence of nickel catalyst at higher temperature and pressure. The Sabatier process is described by the following reaction:

$$
\mathrm{CO}_{2}+4 \mathrm{H}_{2} \rightarrow \mathrm{CH}_{4}+2 \mathrm{H}_{2} \mathrm{O}
$$

Thus, the carbon dioxide containing in biogas is transformed into methane thanks hydrogen produced by the HTSE. The produced water from the Sabatier process would be recycled back to the electrolysis stage, reducing the need of new pure water. The methanation of $\mathrm{CO}_{2}$ is a highly exothermic reaction: the resultant heat is recovered in the integrated heat recovery system and is used to evaporate water and heat steam required for the HTSE. This methanation process has been studied extensively. Recent works obtain a conversion of $\mathrm{CO}_{2}$ greater than $80 \%$ [13].

\subsection{Flow Sheet of the Process}

Figure 2 shows the simplified process flow diagram. The simulation of the processes has been carried out by 


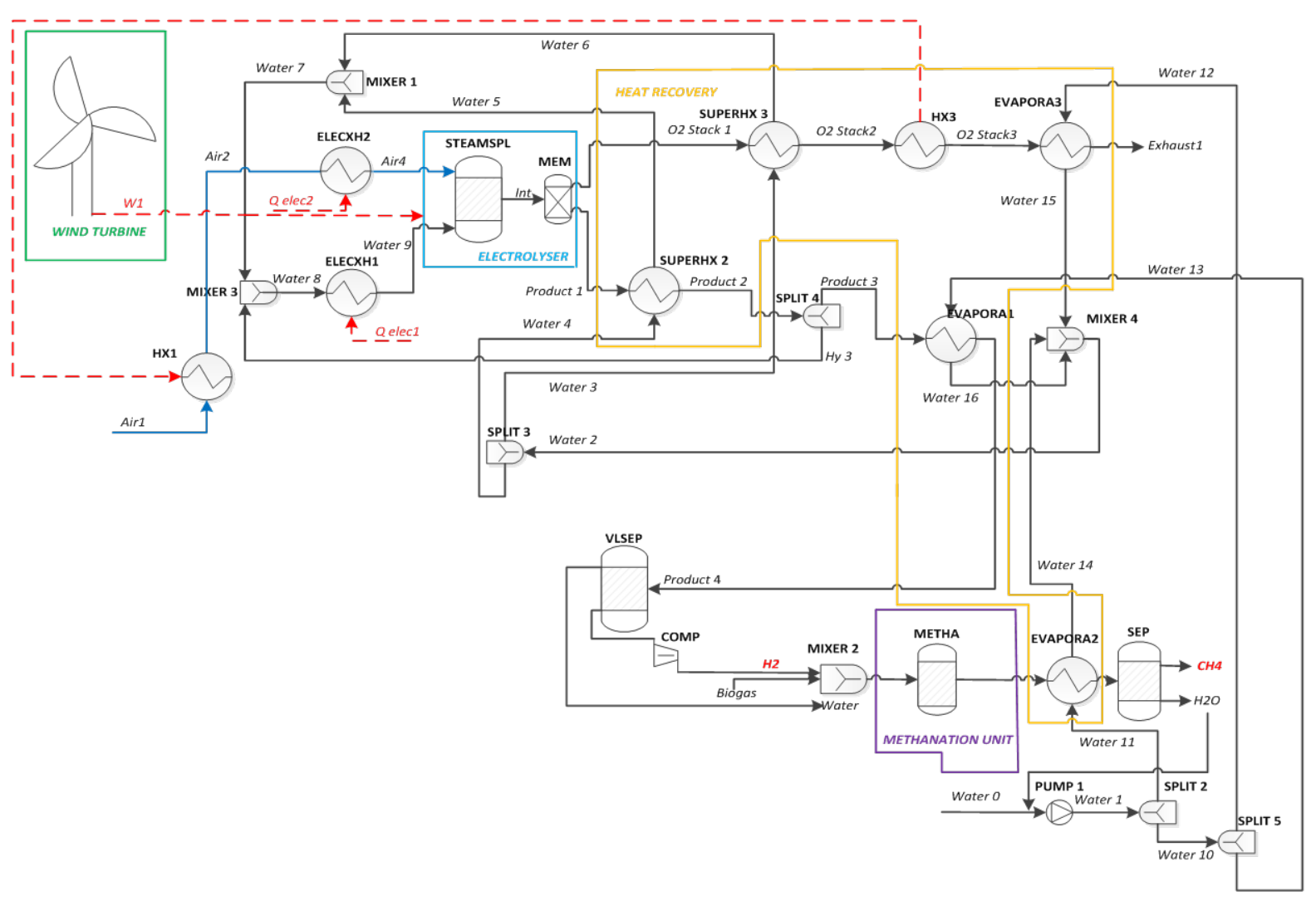

Figure 2. Flow diagram of the wind turbine coupled with HTSE and combined with methanation unit.

using the commercial software simulation tool Aspen Plus ${ }^{\circledR}$. Electricity required for the electrolyser is produced by the wind turbine. The HTSE works at $700^{\circ} \mathrm{C}$ and 1 bar. It is fed with steam at $700^{\circ} \mathrm{C}$ and 1.5 bar. Air at atmospheric pressure is heated up to a temperature of about $700^{\circ} \mathrm{C}$ to serve as sweep gas in the electrolyser.

Before entering the electrolyser, steam is split into two sub-streams which are overheated in heat exchangers by the streams leaving the electrolyser, before being mixed again. The steam is also mixed with a part of the cathode outlet mixture (produced hydrogen and unreacted steam) in order to have a feed stream of $90 \%$ vol water and $10 \%$ vol hydrogen to ensure reducing conditions and prevent oxidation of the cathode. The steam is supplied to the cathode side and is split into hydrogen and oxygen ions within the HTSE. The oxygen ions are transferred through the electrolyte to the anode side, where they form oxygen. Exhaust lines of the HTSE stack are coupled with a heat recovery system. This heat recovery system consists of two heat exchangers, where steam entering the electrolyser is heated up to $700^{\circ} \mathrm{C}$. The produced hydrogen is compressed to 30 bars and sent to the methanation unit for the methane production with carbon dioxide from biogas. The heat generated by the methanation reaction is recovered in the heat recovery system and used to evaporate the water required for the HTSE.

A plant capacity of $10 \mathrm{MWel}$ is considered. The technical performance of this concept was already investigated in previous paper [14]. A flow sheet of a $10 \mathrm{M}$ Wel plant was elaborated and the process was simulated with commercial tool Aspen Plus ${ }^{\circledR}$. An annual production of 1104 metric tons per year (Mt/a) hydrogen and thus of $5888 \mathrm{Mt} / \mathrm{a}$ methane was reached. The overall plant efficiency was calculated to be $38 \%$ [14].

\section{Methodology}

\subsection{Energy Criteria Consideration}

To select an adequate location for the proposed hydrogen production plant, there are some factors to consider. The suitability of locations depends on the energy sources and water source availability. Moreover, the location of the pipelines in which the methane can be fed to is also important. In order to connect the production with the demand side, the link between them, i.e. the distribution infrastructure, has actually to be identified. First it is 
determining to take into account the data relative to the energy source. In the case of the coupling of the HTSE with a wind turbine and a methanation unit, wind energy resource producing the electricity required for the HTSE has to be considered as well as biomass resource needed for the methanation.

Wind power has a number of particularities mainly due to its variable nature. The two most significant issues with wind power are its location and its intermittency. It first requires assessing the wind at a given site. Wind conditions must be measured over a period of several months at least and preferably for a year or more. The output power of wind turbines depends on the intensity of the wind: for the same sized blades, greater wind speed means that the theoretical power that can be extracted increases more than proportionally. The intensity of the wind depends on topographical characteristics of the land. One fundamental circumstance is how rough the terrain is: on plains or at the sea the wind blows with greater intensity than in rolling countryside or around cities. Another element to take into account is the altitude of the land: the higher it is, the greater the wind speed is. Concerning the European wind resources, Scandinavia, the United Kingdom, Ireland, Denmark, the north coast of France, Belgium, Holland and Germany have the most favourable conditions for developing wind power in Europe [15]. The cut-in speed of the turbines is the minimum wind speed at which the blades begin to rotate and produce usable electrical power; typically, this is between 3 and $4 \mathrm{~m} / \mathrm{s}$. It generally requires taking an average of the wind speed over the year greater than $4 \mathrm{~m} / \mathrm{s}$ to consider a wind power energy system. However, it is advisable to have speeds of more than $4 \mathrm{~m} / \mathrm{s}$. These wind turbines must be installed in unobstructed, open areas clearly exposed to the prevailing winds. Rated output speed is the minimum wind speed at which the turbine will generate its rated design output. For example, a $10 \mathrm{~kW}$ wind turbine will not generate $10 \mathrm{~kW}$ until the wind speed reaches the rated output wind speed. At wind speeds between the cut-in speed and the rated output speed, the output power is proportional to the wind speed cubed. At very high speeds, typically $25 \mathrm{~m} / \mathrm{s}$, most wind turbines cease producing energy and shut down. The wind speed at which this occurs is called cut-out speed. Cutout speeds are set for safety purposes to protect the wind turbine from damage.

Figure 3 shows a sketch of how the power output from a wind turbine varies with a steady wind speed.The other important parameter determining the output of a wind farm is the wind speed distribution. This distribution describes, for a particular site, the frequency of wind blowing, detailing speed and direction. This often-overlooked characteristic is important because it is the combination of wind speed distribution and power curve of the proposed turbine which together determines how much energy is produced.

A "wind rose" is the term given to the way in which the joint wind speed and direction distribution is defined. An example is given in Figure 4. The wind rose can be thought of as a wheel with spokes, spaced, in this example, every 30 degrees. For each direction, the wind speed frequency is detailed separately. The frequency and speed at which wind blows from this direction is shown by the length of the spoke and by the thickness of the spoke, respectively. In this example, the wind blows around $45 \%$ of the time from the southwest direction (W $11.5 \%$, WSW $11 \%$, SSW $11 \%$, S $13.5 \%$ ).

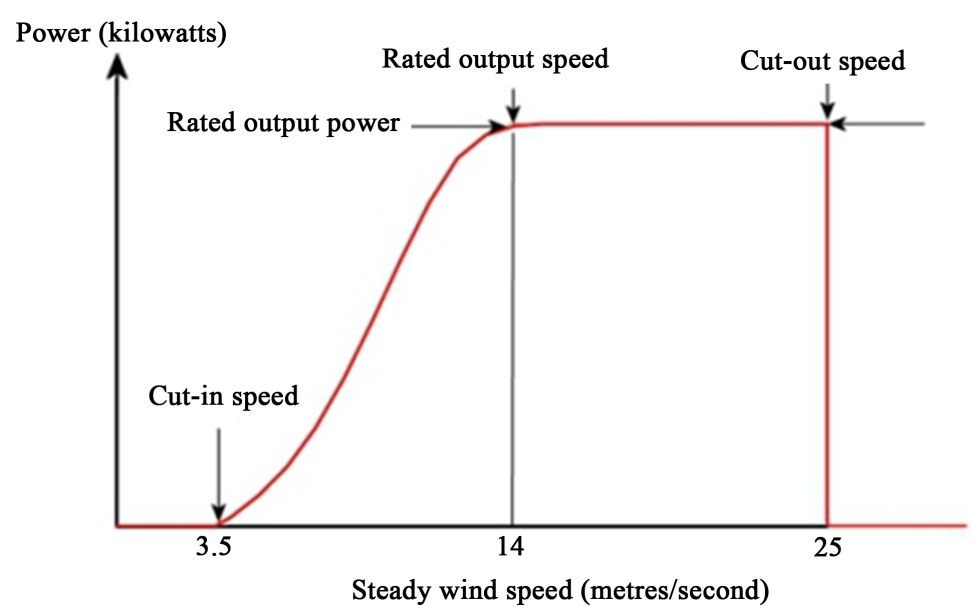

Typical wind turbine power output with steady wind speed.

Figure 3. Wind turbine power output variation with steady wind speed [16]. 


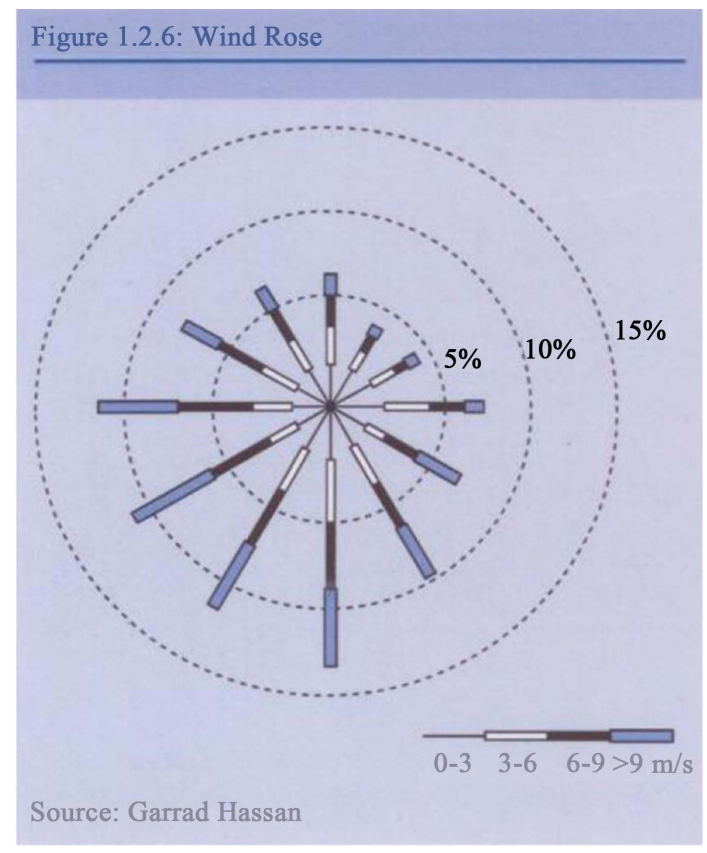

Figure 4. Wind Rose [17].

The design of a wind farm is sensitive to the shape of the wind rose for the site. In some areas, particularly in areas where wind is driven by thermal effects, wind can be very unidirectional.

In Northern Europe, the wind, although predominantly from the southwest, also comes from other directions for a significant amount of time, and hence wind turbines tend to be more uniformly spaced in all directions.

Nevertheless, wind speed alone is not enough to describe the potential energy from the site. More realistic site wind speed distributions are shown in Figure 5. This figure shows actual wind speed distribution as well as a "Weibull fit" to the distribution. The Weibull distribution is a mathematical expression which provides a good approximation to many measured wind speed distributions. It is therefore frequently used to characterise a site.

Such a distribution is described by two parameters: the Weibull 'scale,' parameter which is closely related to the mean wind speed, and the 'shape' parameter, which is a measurement of the width of the distribution.

This approach is useful since it allows both the wind speed and distribution to be described concisely. However, as can be seen from the figure, care must be taken in using a Weibull fit.

For many sites it may provide a good likeness to the actual wind speed distribution, but there are some sites where differences may be significant.

The second energy source to consider in the studied case is the biomass. Biomass is a renewable energy source and mainly consists of carbon, hydrogen and oxygen. There are several sources for biomass energy: biomass resource from primary production and biomass resource in form of processing waste. Biomass resource from primary production includes wood-based biomass and straw-based biomass.

The biomass potential depends thus on the use of land area and farming practices.

The main biomass resources can be listed as follows:

- Short rotation forestry (Willow, poplar, eucalyptus).

- Herbaceous lingo-cellulosic crops (Miscanthus).

- Sugar crops (Sugar beet, sweet sorghum, Jerusalem artichoke).

- Starch crops (Maize, Wheat).

- Oil crops (Rape seed, sunflower).

- Wood wastes (Forest residues, wood processing, waste, construction residues).

- Agricultural residues and wastes (Straw, animal manure, etc.).

- Organic fraction of municipal solid waste and refuse.

- Sewage sludge.

- Industrial residues (e.g. from the food and the paper industries). 


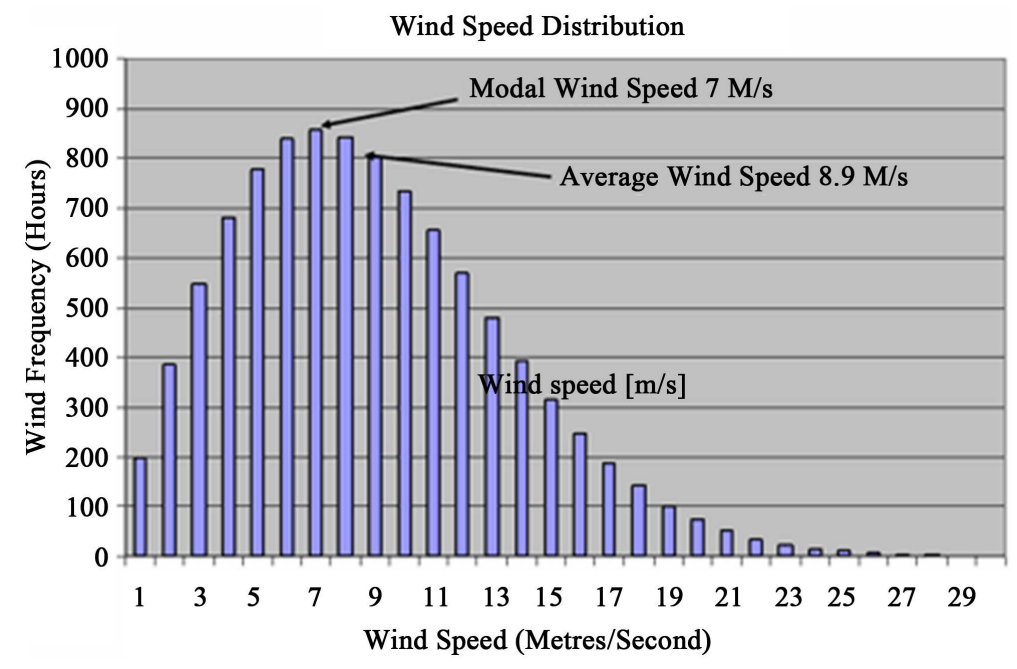

Figure 5. Example of wind speed distributions [17].

Concerning the primary production of biogas in Europe, Germany was in 2006 the first producer with 1923.2 kilotons of oil equivalent [18].

The last resource to consider is water. In fact the assurance of adequate water supply for steam production and as feed for the electrolyser has to be considered when designing the plant. Water resources are often present in windy region, in particular in North Europe. Moreover it is possible to desalinate seawater. The original concept is based in the idea boiling or evaporating water separates water from salt [19].

\subsection{Geographical Consideration}

After having taken into account the different energy factors, it is also important to consider the physical characteristics of the site in order to assure the safety and security measures. Geological, seismological, and geophysical data must be provided to clearly establish whether there is a potential for surface deformation which may affect the design and operation of the plant. Moreover it is necessary to know the snowfall (normal conditions and extreme conditions) as well as the ambient air temperature (maximum and minimum) for normal and extreme conditions.

\subsection{Hydrogen Economy}

The infrastructures as well as economic considerations need to be taken into account. The determination of the plant location will allow defining further boundary conditions of the plants. Beside the location of the hydrogen production plant, it is also important to identify the future hydrogen market. Finally, in order to connect production with demand side, the link between them, i.e. the distribution infrastructure, has to be investigated. In the present study the hydrogen produced by the plant will be used to produce methane from hydrogen and $\mathrm{CO}_{2}$ following the Sabatier process, which is nowadays commercially used. The methane will be then compressed and transported via pipelines in west and south Germany. A proven infrastructure with large storage capacity and a powerful distribution network is available in Germany and the produced methane of our plant can be fed into this natural gas grid and stored there. In 2009, about 914 TWh of natural gas was taken from the German network, of which about a quarter for households. The transmission network has a length of nearly $47,000 \mathrm{~km}$. The natural gas network transports today an energy of 1.000 TWh [20]. Huge storage capacity in the form of storage tanks and pipelines are already available in many countries capable to store a significant share of the country's energy consumption.

\section{Results and Discussion}

Wind and biogas energy data were investigated as well as water resources. The world's total installed wind power reached the level of 39,249 MW by the end of 2003, which was enough to meet the demand of seventeen 
million households [18]. The total wind power installed in Europe by the end of 2003 was 28,490 MW, equalling $72.6 \%$ of the total worldwide. Predictions for 2030 made by the European Wind Energy Association are now being revised upwards. While estimates for 2010 were for 40,000 MW of installed power, 84,000 MW were reached in 2010 in the EU (and 198,000 MW worldwide). In 2012, the total installed wind power capacity has reached 110,000 MW in the EU and 282,000 MW worldwide. This leads one to think that the initial objective of reaching 100,000 MW by 2030 will in fact become 170,000 MW. Concerning the installed power of wind energy in Europe in 2010 Germany has the largest capacities in absolute terms [18].

In Germany, the region of Schleswig-Holstein is one of the regions with the largest wind reserves (see Figure 6) [21]. Moreover this region is situated on the coasts and has good resource in water [22].

The standard wind turbine operates in an ambient temperature range of $-20^{\circ} \mathrm{C}$ to $40^{\circ} \mathrm{C}$.

Concerning the ambient air temperature in Schleswig Holstein, the levels are not a problem for the proposed technology [22].

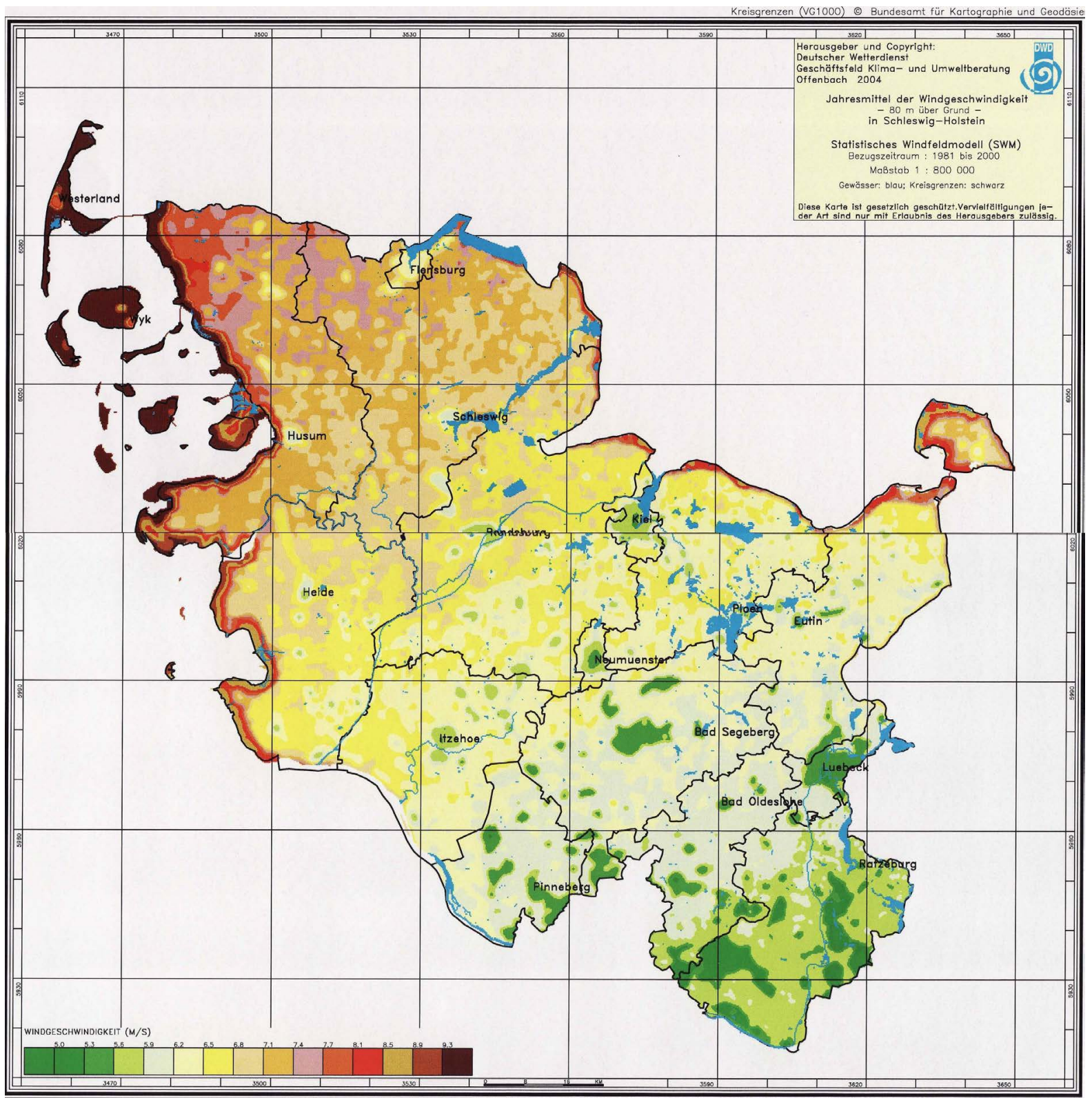

Figure 6. Wind map in Schleswig-Holstein-annual average 1981-2000 [21]. 
At the end 2010, 2600 wind power plants corresponding to a total of 2900 MW were in operation in SchleswigHolstein. With the existing plants, the repowering and the realization of the six planned offshore wind parks, considerably more electricity as needed in this region could be produced [23].

Moreover, the biomass potential is enough to cover $20 \%$ of the final energy consumption in 2020, if $20 \%$ of the agricultural area is used for the production of energy feedstock [23].

North Germany meets the requirements needed for the technology presented in this paper concerning energy resources and meteorological conditions as well as geographical considerations, offering a lot of wind and biomass, as well as enough water resource. Moreover Schleswig-Holstein has already experience in wind power as well as in biogas technology. The energy won from the wind in North of Germany can be transported where it is needed like in the South of Germany where the wind energy technology is not so developed like in the North.

\section{Conclusions}

In order to integrate the fluctuating wind energy.the transformation of the energy supply needs further development of storage technologies. The conversion of renewable wind power into green methane offers a technical approach with the necessary storage and transport capacities. Thus, the HTSE unit coupled to the wind energy and a methanation unit is analyzed regarding the site selection and the definition of the boundary conditions in regard to the required conditions for the plant location. The hydrogen produced by a HTSE combined with a wind turbine is used for the production of methane, which is then injected in the natural gas grid.The coupling of the HTSE with wind energy enables thus to manage the energy production and demand. The technology can actually store electrochemically the surplus energy by producing hydrogen. Hydrogen can be used to produce methane which can be then transported where it is needed. The site of the proposed hydrogen production plant is selected regarded the energy resources, the water source, the distribution infrastructure and geographical consideration. It is found that the best location for the proposed plant will be the north of Germany due to geographical considerations as well as its wind power reserves, its water and biomass resources.

This study is limited first to the European area but it will be interesting to consider other parts of the world in a future work. Moreover, the demonstration of the durability of the HTSE system has to be done. This concept will attract more and more attention with growing interest in hydrogen and in renewable energy.

\section{Acknowledgements}

The authors of this paper gratefully acknowledge the co-funding of the projects ADEL (Grant agreement No. 256755) and SOPHIA (Grant agreement No. 621173) by the FCH JU.

\section{References}

[1] Beerepoot, M. and Marmion, A. (2012) Policies for Renewable Heat: An Integral Approach. OECD/IEA, Paris.

[2] IEA (2007) Mind the Gap: Quantifying Principal-Agent Problems in Energy Efficiency. OECD/IEA, Paris.

[3] BMU (2010) Nationaler Biomasseaktionsplan für Deutschland, Beitrag der Biomasse für eine nachhaltige Energieversorgung, R.K.I. BMU, BMELV Referat N2, Editor 2010.

[4] Mai, T., Sandor, D., Wiser, R. and Schneider, T. (2012) Renewable Electricity Futures Study: Executive Summary, C.N.R.E.L. NREL/TP-6A20-52409-ES. Golden.

[5] Pfaffel, S., Berkhout, V., Faulstich, S., Kühn, P., Linke, K., Lyding, P. and Rothkegel, R. (2012) Windenergie Report Deutschland, F.I.f.W.u.E. IWES.

[6] Green, R., Hu, H. and Vasilakos, N. (2011) Turning the Wind into Hydrogen: The Long-Run Impact on Electricity Prices and Generating Capacity. Energy Policy, 39, 3992-3998. http://dx.doi.org/10.1016/j.enpol.2010.11.007

[7] (2013) JTI-FCH Project ADEL. www.adel-energy.eu

[8] Varone, A. and Ferrari, M. (2015) Power to Liquid and Power to Gas: An Option for the German Energiewende. Renewable and Sustainable Energy Reviews, 45, 207-218. http://dx.doi.org/10.1016/j.rser.2015.01.049

[9] Brisse, A., Schefold, J., Stoots, C. and O’Brien, J. (2010) Electrolysis Using Fuel Cell Technology. In: Lehnert, W. and Steinberger-Wilckens, R., Eds., Innovation in Fuel Cell Technologies Editors, RSC Publishing, Cambridge, 263-286.

[10] Zahid, M., Schefold, J. and Brisse, A. (2010) High-Temperature Water Electrolysis Using Planar Solid Oxide Fuel Cell Technology: A Review. In: Stolten, D., Ed., Hydrogen and Fuel Cells, Fundamentals, Technologies and Applications, Wiley-VCH, Weinheim, 227-242. 
[11] Udagawa, J., Aguiar, P. and Brandon, N.P. (2007) Hydrogen Production through Steam Electrolysis: Model-Based Steady State Performance of a Cathode Supported Intermediate Temperature Solid Oxide Electrolysis Cell. Journal of Power Sources, 166, 127-136. http://dx.doi.org/10.1016/j.jpowsour.2006.12.081

[12] Houaijia, A., Roeb, M., Monnerie, N. and Sattler, C. (2013) Process Design and Dynamic Simulation of Solar Hydrogen Production via Intermediate Temperature Steam Electrolysis in IRES. Berlin.

[13] Müller, K., Fleige, M., Rachow, F. and Schmeißer, D. (2013) Sabatier Based $\mathrm{CO}_{2}$-Methanation of Flue Gas Emitted by Conventional Power Plants. Energy Procedia, 40, 240-248. http://dx.doi.org/10.1016/j.egypro.2013.08.028

[14] Monnerie, N., Roeb, M., Houaijia, A. and Sattler, C. (2014) Coupling of Wind Energy and Biogas with a High Temperature Steam Eleectrolyser for Hydrogen and Methane Production. Green and Sustainable Chemistry, 4, 60-69. http://dx.doi.org/10.4236/gsc.2014.42010

[15] (1989) The European Wind Atlas, Roskilde. Risø National Laboratory, Roskilde.

[16] http://www.wind-power-program.com/turbine_characteristics.htm

[17] http://www.wind-energy-the-facts.org/the-annual-variability-of-wind-speed.html

[18] (2013) www.eurobserv-er.org

[19] Trieb, F., Müller-Steinhagena, H., Kernb, J., Scharfec, J., Kabaritid, M. and Al Taherd, A. (2009) Technologies for Large Scale Seawater Desalination Using Concentrated Solar Radiation. Desalination, 235, 33-43. http://dx.doi.org/10.1016/j.desal.2007.04.098

[20] (2013) http://www.powertogas.info/power-to-gas/gas-speichern.html

[21] (2013) www.dwd.de

[22] Deutscher Wetterdienst (DWD), A.A. Zentrum für Agrarmeteorologische Forschung Braunschweig (ZAMF)].

[23] (2013).

http://www.schleswig-holstein.de/UmweltLandwirtschaft/DE/ImmissionKlima/05_Erneuerbare_Energien/ein_node.ht $\underline{\mathrm{ml}}$ 